\title{
Identification of a Novel Basic Helix-Loop-Helix Gene, Heslike, and Its Role in GABAergic Neurogenesis
}

\author{
Goichi Miyoshi, Yasumasa Bessho, Shuichi Yamada, and Ryoichiro Kageyama \\ Institute for Virus Research, Kyoto University, Kyoto 606-8507, Japan
}

\begin{abstract}
Neuronal subtype specification depends on multiple transcription factors such as basic helix-loop-helix (bHLH) factors. However, transcription factor codes for most neurons remain to be determined. Here, we report identification of a novel mouse bHLH factor, termed Heslike, that has Hes1-like bHLH domain and transcriptional repressor activity. Heslike is coexpressed with the bHLH factor Mash1 in brain regions that give rise to GABAergic neurons. In the mesencephalon and the caudal diencephalon, coexpression of Heslike and Mash1 is initially restricted to small regions but expanded dorsally from embryonic day 9.5 onward, and this expansion of coexpression is followed by GABAergic neurogenesis. Misexpression of Heslike in mouse embryos generates ectopic GABAergic neurons only from the Mash $1^{+}$region. In contrast, in the mesencephalon and the caudal diencephalon of Mash1-null mice, GABAergic neurons are almost completely missing and, instead, other neurons are generated, although Heslike is still expressed. Furthermore, coexpression of Heslike and Mash1 significantly promotes formation of GABAergic neurons, compared with each gene alone, in neural precursor cell culture. Thus, Heslike or Mash1 alone is not sufficient, but their coexpression may be important for generation of GABAergic neurons. These results suggest that combinations of distinct bHLH factors promote formation of distinct neuronal subtypes, thereby increasing neuronal diversity.
\end{abstract}

Key words: bHLH; diencephalon; GABAergic neuron; Heslike; Mash1; mesencephalon

\section{Introduction}

A wide variety of neurons is generated in a spatiotemporalspecific manner during neural development. The mechanism for generation of such neuronal diversity remains to be determined, but recent studies have revealed that transcription factors with a basic helix-loop-helix (bHLH) domain play an essential role in neurogenesis (Bertrand et al., 2002; Ross et al., 2003). Neuronal bHLH genes such as Mash1 and Math3 are coexpressed by subsets of cells and, in their absence, those cells that would normally differentiate into neurons adopt the glial fate, indicating that these bHLH genes cooperatively regulate neuronal versus glial fate determination (Tomita et al., 2000; Nieto et al., 2001). A neuronal bHLH gene actively inhibits glial differentiation while specifying pan-neuronal characteristics by independent mechanisms (Sun et al., 2001).

Neuronal bHLH genes such as Mash1 and Neurogenin2 $(\mathrm{Ngn2})$ are expressed in a complementary manner and exhibit distinct functions. Mash1 is primarily expressed in the ventral telencephalon and regulates formation of GABAergic interneurons, whereas $\mathrm{Ngn} 2$ is expressed in the dorsal telencephalon and

Received Dec. 3, 2003; revised Feb. 23, 2004; accepted Feb. 24, 2004.

This work was supported by research grants from the Ministry of Education, Culture, Sports, Science, and Technology of Japan and by the Japan Society for the Promotion of Science. We thank Dr. François Guillemot for Mash1null mice. Monoclonal antibodies to Nkx2.2, Pax6, and Shh were obtained from the Developmental Studies Hybridoma Bank (University of lowa). G.M. was supported by the 21st Century Center of Excellence Program of the Ministry of Education, Culture, Sports, Science, and Technology of Japan.

Correspondence should be addressed to Ryoichiro Kageyama, Institute for Virus Research, Kyoto University, Shogoin-Kawahara, Sakyo-ku, Kyoto 606-8507, Japan. E-mail: rkageyam@virus.kyoto-u.ac.jp. DOI:10.1523/JNEUROSCI.5327-03.2004

Copyright $\odot 2004$ Society for Neuroscience $\quad$ 0270-6474/04/243672-11\$15.00/0 regulates formation of glutamatergic pyramidal neurons (Fode et al., 2000; Parras et al., 2002). Thus, bHLH genes regulate neuronal subtype identity in addition to specifying pan-neuronal characteristics. Interestingly, it was shown that combinations of distinct bHLH genes further increase the repertoire of neuronal and glial subtypes. A combination of the bHLH genes Ngn2 and Olig2 promotes motor neuron formation (Mizuguchi et al., 2001; Novitch et al., 2001), whereas each gene alone generates other neurons and oligodendrocytes, respectively (Lu et al., 2001, 2002; Zhou et al., 2001; Zhou and Anderson, 2002). However, the bHLH gene codes for such cell-type specification are mostly unknown.

GABAergic neurons are the principal inhibitory interneurons in brain functions. It has been shown that GABAergic neurons are born in the ventral telencephalon and migrate tangentially to the dorsal telencephalon (De Carlos et al., 1996; Anderson et al., 1997a; Tamamaki et al., 1997; Corbin et al., 2001), in contrast to the excitatory glutamatergic neurons that migrate radially along the radial fibers. In addition to the bHLH gene Mash1, the homeodomain genes $N k \times 2.1, D l \times 1 / 2$, and Gsh2 are involved in formation of GABAergic neurons in the telencephalon (Anderson et al., 1997a,b; Casarosa et al., 1999; Sussel et al., 1999; Corbin et al., 2000; Marín et al., 2000; Toresson et al., 2000; Yun et al., 2002). Although GABAergic neurons are differentiated widely throughout the CNS, expression of $N k \times 2.1$ and $D l \times 1 / 2$ is restricted to the forebrain (Shimamura et al., 1995). Thus, the factors that induce GABAergic neuron formation in other brain regions remain to be determined.

Here, we report identification of a novel bHLH gene, termed Heslike, that has Hes1-like bHLH domain and transcriptional 


\section{A bHLH domain}

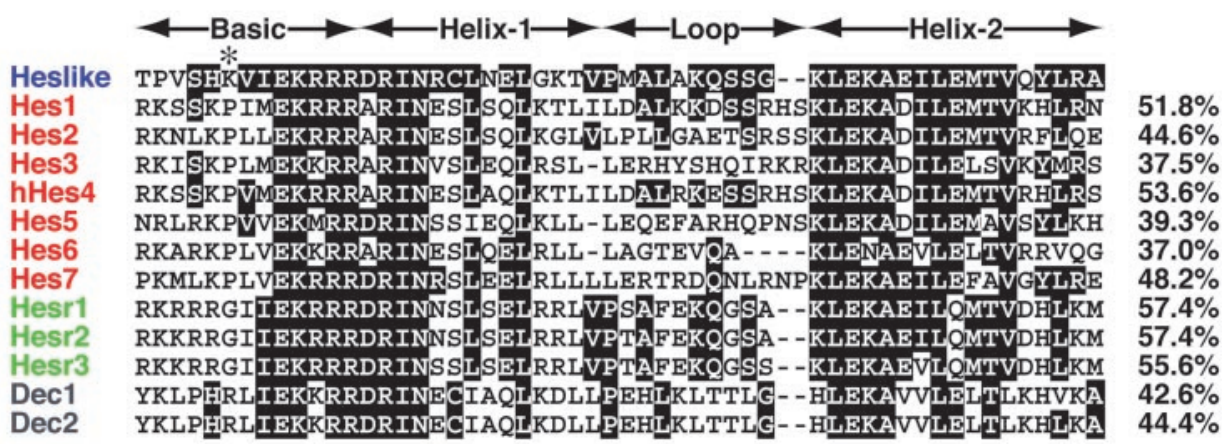

\section{B Orange domain}
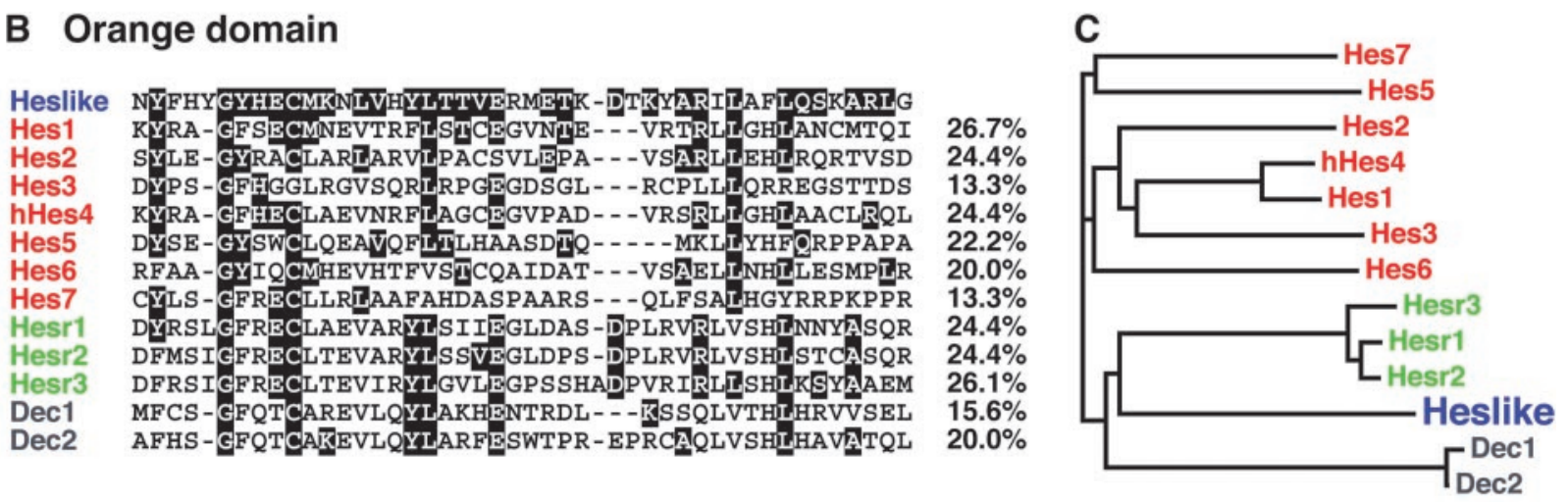

D

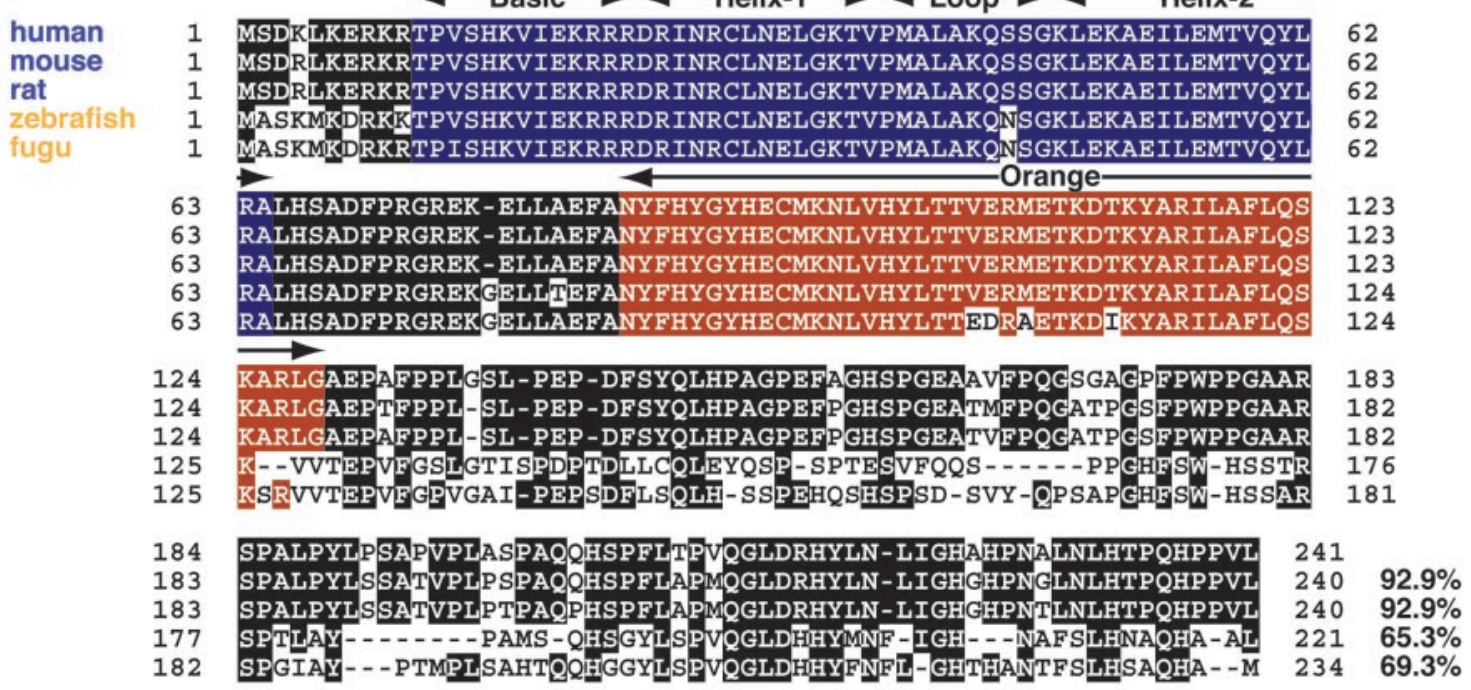

Figure 1. Sequence comparison of Heslike and its related bHLH factors. A, Sequence comparison of the bHLH domains. Heslike has a high sequence homology to Hes, Hesr, and Dec factors. However, the proline- glycine residues conserved among Hes and Hesr factors, respectively, in the middle of the basic region are not present in Heslike (asterisk). B, Sequence comparison of the Orange domains. Heslike has a low sequence homology to Hes, Hesr, and Dec factors. C, Phylogenetic tree of Heslike and its related bHLH factors. The tree was drawn using the Bootstrap NJ tree method on the basis of the bHLH domains. Heslike constitutes a distinct subfamily from Hes/Hesr/Dec factors. D, Sequence comparison of vertebrate Heslike factors. Heslike is conserved in vertebrates such as human, mouse, rat, zebrafish, and fugu. Conserved amino acid residues are shown in the box.

repressor activity. Heslike is coexpressed with Mash1 in brain regions that give rise to GABAergic neurons. We found that these two bHLH factors cooperatively promote generation of GABAergic neurons, whereas Heslike or Mash1 alone cannot. These results suggest that combinations of distinct bHLH factors promote formation of distinct neuronal subtypes, thereby increasing neuronal subtype diversity.

\section{Materials and Methods}

Isolation and characterization of Heslike cDNA. Reverse transcriptase (RT)-mediated PCR was performed against mouse embryonic day (E) 9.5 mRNA using fully degenerate primers deduced from the amino acid sequences in the bHLH region of Hes1. A PCR clone encoding a novel bHLH amino acid sequence was selected as a probe for screening a mouse E9.5 cDNA library. A full-length cDNA clone was obtained and named 


\section{A 3x UAS - Luciferase}

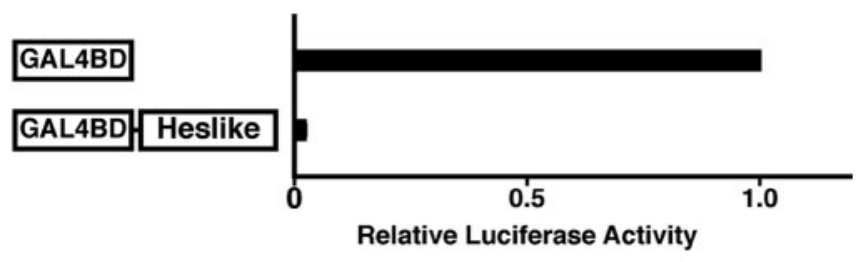

B $\quad 6 \times \mathrm{N}$ box - Luciferase

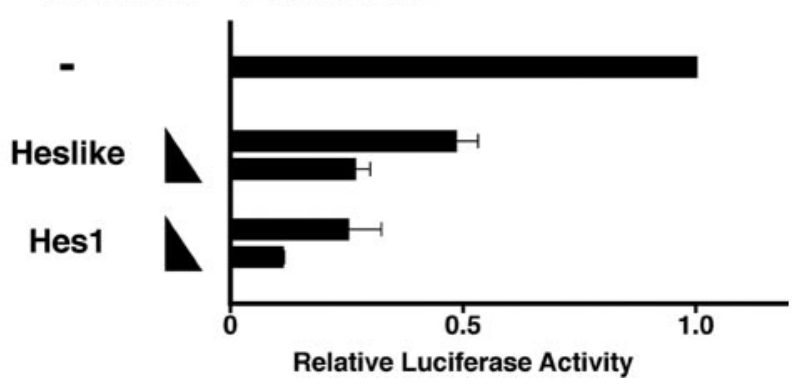

Figure 2. Transcriptional activity of Heslike. A, The expression vector for GAL4BD alone or fused to the $N$ terminus of Heslike was cotransfected into $\mathrm{C} 3 \mathrm{H} 10 \mathrm{~T} 1 / 2$ cells with the reporter under the control of three repeats of the UAS. B, The expression vector (25 or $100 \mathrm{ng}$ ) for Heslike or Hes 1 was cotransfected into $\mathrm{C} 3 \mathrm{H} 10 \mathrm{~T} 1 / 2$ cells with the reporter under the control of six repeats of the $\mathrm{N}$ box elements. Each value with an SE represents four independent experiments performed in duplicate.

Heslike for its high homology in the bHLH region to Hes and Hesr genes. Mouse Heslike genomic clones were also isolated and sequenced. Human, mouse, rat, zebrafish, and fugu genomic sequences were obtained by Basic Local Alignment Search Tool search using the GenBank genome database and compared with the mouse sequence.

Luciferase assay. The reporter plasmid contained the firefly luciferase gene under the control of the thymidine kinase (TK) promoter with three repeats of the upstream activating sequence (UAS) sequences or the $\beta$-actin promoter with six repeats of the $\mathrm{N}$ boxes. The luciferase reporter $(0.1-0.2 \mu \mathrm{g})$ and the expression vector for Heslike, Hes1, or the fusion of the GAL4 DNA-binding domain and Heslike (25-300 ng) were transfected with the FuGENE6 transfection reagent (Roche, Indianapolis, IN) into $\mathrm{C} 3 \mathrm{H} 10 \mathrm{~T} 1 / 2$ cells, which were cultured in 12-multiwell plates. Five nanograms of the plasmid containing Renilla luciferase gene under the control of either the SV40 promoter, pRL-SV40 vector (Promega, Madison, WI), or the TK promoter pRL-TK (Promega) was also transfected as an internal standard to normalize the transfection efficiency. The total DNA amount was adjusted with the pCI vector. After $48 \mathrm{hr}$, the cells were harvested, and the luciferase activity was measured.

Animals and genotyping. All animals used in this study were maintained and handled according to protocols approved by Kyoto University. Genotyping of Mash1-mutant mice (Guillemot et al., 1993) was performed by PCR using the following primers: the wild-type sense, 5'-ACGACTTGAACTCTATGGCGGGTTCTC-3'; the wild-type antisense, 5'-GCCACTCTCAGGGGCCAAGACTGAAGTTAA-3'; and the mutant sense, 5'-AAATTAAGGGCCAGCTCATTCCTCCACTCA-3'. These primers produce 350 and $280 \mathrm{bp}$ fragments from the wild-type and mutant alleles, respectively.

Antibodies. cDNA for Heslike fused with the $6 \times$ His tag sequence at the $\mathrm{N}$ terminus was cloned into pMNT T7 expression vector (Hirata et al., 2000). For efficient protein expression in E. coli, the codon usage of the first $200 \mathrm{bp}$ sequence of Heslike cDNA was changed to the one frequently used in E. coli. Recombinant Heslike protein was expressed in the E. coli strain BL21(DE3)pLysS (Stratagene, La Jolla, CA) and isolated by SDS-PAGE. The band with the correct size was cut out and homogenized with an equal volume of the Freund complete adjuvant (Difco, Detroit, MI). Immunogen $(0.1 \mathrm{mg}$ ) was given to Hartley guinea pigs (4 weeks of age) by intradermic multisite injection. With a 4 week interval, a single booster injection with the same volume of immunogen was performed using the Freund incomplete adjuvant (Difco). Eight days later, the whole blood was collected by cardiac puncture, stored at $4^{\circ} \mathrm{C}$ overnight, and centrifuged to separate the serum. This serum was used at a 1:500 dilution.

The following antibodies were used at the indicated dilutions: antiphosphorylated histone 3 (Sigma, St. Louis, MO; 1:500), anti-Ki67 (BD PharMingen, San Diego, CA; 1:500), anti- $\beta$-Tubulin III (TuJ1) (Babco, Richmond, CA; 1:500), anti-glutamic acid decarboxylase 65 (GAD65) (BD PharMingen; 1:1000), anti-Mash1 (BD PharMingen, 1:1000), antiGABA (Sigma; 1:2000), anti-Nkx2.2 (Developmental Studies Hybridoma Bank, University of Iowa, IA; 1:200), anti-Pax6 (Developmental Studies Hybridoma Bank; 1:200), anti-Shh (Developmental Studies Hybridoma Bank; 1:100), and anti-green fluorescent protein (GFP) conjugated with Alexa-488 (Molucular Probes, Eugene, OR; 1:500). As secondary antibodies, those conjugated with biotin (Vector Laboratories, Burlingame, CA), Alexa-488, Alexa-594 (Molecular Probes), cyanine 3 (Chemicon, Temecula, CA), or FITC (Jackson ImmunoResearch, West Grove, PA) were used.

RNA in situ hybridization and immunohistochemistry. Section and whole-mount RNA in situ hybridization was performed using digoxigenin-labeled Heslike antisense and sense RNA probes as described previously (Hirata et al., 2001).

For immunohistochemistry, brains and embryos were fixed in $4 \%$ formaldehyde in PBS at room temperature for $30 \mathrm{~min}$. Tissues were rinsed in PBS, treated in $25 \%$ sucrose overnight at $4^{\circ} \mathrm{C}$, mounted in OCT compound, and sectioned. Sections were washed in PBS, blocked for $1 \mathrm{hr}$ with PBS containing $1.5 \%$ goat serum and $0.1 \%$ Triton X-100, and incubated overnight at $4^{\circ} \mathrm{C}$ with primary antibodies diluted in the same blocking reagent. The sections were next washed three times in PBS and incubated with secondary antibodies for $1 \mathrm{hr}$ at room temperature. Fluorescent images were obtained using a confocal microscope (LSM510; Zeiss, Jena, Germany) and a CCD camera (AxioCam; Zeiss).

Generation of transgenic mice. We constructed a plasmid that contains $2.5 \mathrm{~kb}$ rat Nestin promoter region, SV40 early mRNA polyadenylation signal, and $1.8 \mathrm{~kb}$ rat Nestin second intron between the NotI and XhoI sites in pBluescriptII SK + vector. cDNA for mouse Heslike was cloned into the SalI site of the plasmid. The resultant $5.3 \mathrm{~kb}$ NotI-XhoI DNA fragment, which contains the Heslike cDNA under the control of the Nestin promoter-enhancer, was isolated and injected into the male pronucleus. Embryos were collected at E10.5-E11.5. Embryos were genotyped by PCR using the following primers: Nestin promoter sense, $5^{\prime}$ CTCCGCTTCCGCTGGGTCACTGTC-3'; and Heslike third exon antisense, $5^{\prime}$-TACTGCACTGTCATCTCCAGGATC- $3^{\prime}$. These primers produced a $300 \mathrm{bp}$ fragment from the transgene allele.

Neural precursor cell culture. In the expression vectors, the coding region for Heslike and Mash1 was placed under the control of the elongation factor $1 \alpha$ promoter. In addition, enhanced GFP fused with three repeats of the nuclear localization signal of the SV40 large T antigen at the $\mathrm{N}$ terminus was expressed together through the internal ribosomal entry site. We performed electroporation of the expression vectors to brains of E11.5 mouse embryos as described previously (Ohtsuka et al., 2001). Next, neural precursor cells were prepared from the electroporated brains as described previously (Ohtsuka et al., 2001) and cultured for $3 \mathrm{~d}$ in DMEM-F12 medium containing B27 and N2 supplement (Invitrogen, Grand Island, NY). Cell types were analyzed by immunocytochemistry.

\section{Results}

\section{Identification of a novel bHLH gene Heslike}

To identify a novel bHLH gene, we performed RT-PCR using primers homologous to the bHLH domain of Hes1. We identified a bHLH gene, termed Heslike (GenBank accession number AB098077 of mouse Heslike cDNA), from cDNA library of mouse embryos at E9.5. Heslike has a high sequence homology in the bHLH domain (Fig. 1A) and a weak homology in the Orange domain (Fig. 1B) to Hes (Sasai et al., 1992) and Hesr factors (Kokubo et al., 1999; Leimeister et al., 1999; Nakagawa et al., 1999; Chin et al., 2000; Zhong et al., 2000; Iso et al., 2001). However, it lacks proline-glycine residues in the middle of the basic 

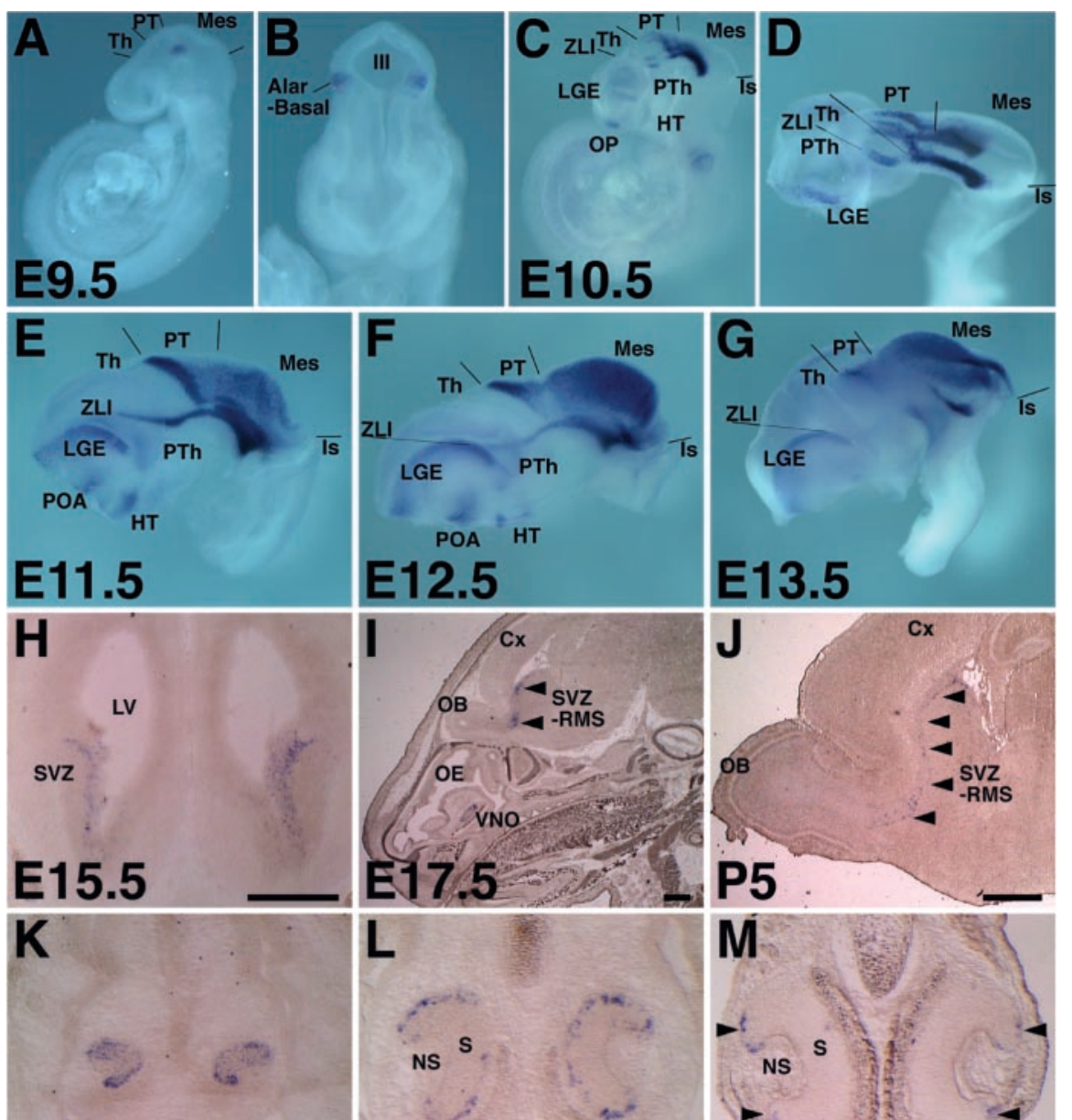

\section{E13.5}
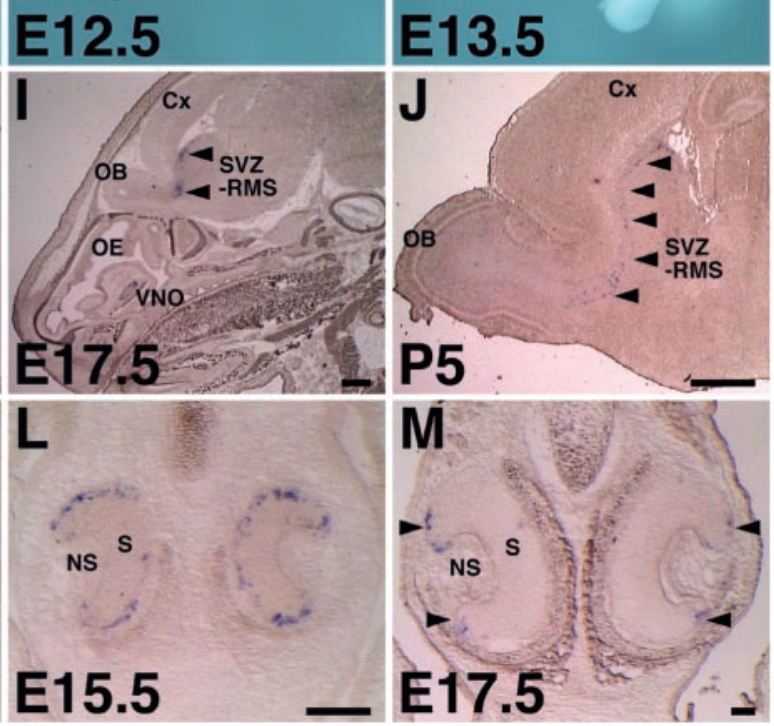

Figure 3. In situ hybridization analysis of Heslike. A, B, At E9.5, Heslike is detectable around the alar-basal boundary of the mesencephalon. C, D, At E10.5, Heslike expression domain is expanded caudally toward the isthmus. Rostrally, the expression domain is split into two stripes. The ventral stripe is extended to the ZLI, whereas the dorsal stripe ends in the pretectum (PT). Heslike is also expressed in the olfactory placode (OP), LGE, and prethalamus (PTh). E-G, Heslike expression is upregulated during E11.5-E13.5. In addition, it is expanded dorsally in the PT and mesencephalon (Mes). The expression also occurs in the preoptic area (POA) and hypothalamus (HT). H, Transverse section of the telencephalon. Heslike is expressed in the subventricular zone (SVZ). I, J, Parasagittal sections. Heslike is expressed in the SVZ-rostral migratory stream (RMS). K-M, Transverse sections. Heslike is expressed in the sensory epithelium $(S)$ of vomeronasal organ. Heslike ${ }^{+}$domain becomes restricted to the basal layer at E15.5 $(L)$ and later occupies the small region close to the nonsensory epithelium (NS) ( $M$, arrowheads). $C x$, Cortex; III, third ventricle; Is, isthmus; LV, lateral ventricle; $O B$, olfactory bulb; $0 E$, olfactory epithelium; Th, thalamus; VNO, vomeronasal organ. Scale bars: $H-J$, $500 \mu \mathrm{m} ; K-M, 100 \mu \mathrm{m}$.

region, which are conserved in Hes-Hesr, respectively, and instead it has a lysine residue (Fig. $1 \mathrm{~A}$, asterisk). Because the amino acid residue at this position is known to be important for specific DNA binding (Davis et al., 1990), Heslike could bind to a sequence different from the Hes-Hesr-binding sites, although Heslike protein generated in vitro can bind to the $\mathrm{N}$ box on gel shift assay, like Hes1 (data not shown). In addition, Heslike does not have WRPW-YRPW sequences at the carboxy terminus (Fig. $1 D)$, which are conserved by Hes-Hesr factors, respectively. Because the WRPW sequence is known to function as a repression domain by recruiting the corepressor TLE/Grg (Paroush et al., 1994; Grbavec and Stifani, 1996), Heslike could have a transcriptional activity different from Hes. On the basis of the bHLH sequence comparison, it is likely that Heslike constitutes a related but distinct subfamily (Fig. 1C). Database analysis indicates that Heslike is conserved in other vertebrates, including human, rat, zebrafish, and fugu (Fig. 1D) but not in invertebrates such as Drosophila, ascidian, and C. elegans. In addition, using database searching, we did not find a gene more closely related to Heslike than Hes, Hesr, and Dec.

\section{Heslike acts as a}

\section{transcriptional repressor}

To analyze the transcriptional activity of Heslike, we performed a transient transfection assay. We first examined the transcriptional activity of Heslike fused with the DNA-binding domain of GAL4 (GAL4BD), which binds to the UAS sequence. This fusion product efficiently represses transcription from the promoter containing the UAS sequences, whereas GAL4BD alone does not (Fig. 2A). These results indicate that Heslike has a transcriptional repressor activity. Because Heslike can bind to the $\mathrm{N}$ box on gel shift assay (data not shown), we next examined whether Heslike acts as an $\mathrm{N}$ boxdependent transcriptional repressor. As shown in Figure $2 B$, Heslike efficiently represses transcription from the promoter containing $\mathrm{N}$ box sequences, although the repression activity is weaker than Hes1. These results indicate that Heslike acts as a transcriptional repressor.

\section{Expression pattern of Heslike}

To determine the expression pattern of Heslike, we performed in situ hybridization. At E9.5, Heslike expression is first observed bilaterally in restricted regions of the rostral mesencephalon (Fig. $3 A, B$ ). At $\mathrm{E} 10.5$, the Heslike expression domain is expanded caudally toward the isthmus, the boundary between the mesencephalon and rhombencephalon (Fig. 3C,D). Rostrally, the bilateral expression domains are split into dorsal and ventral stripes (Fig. $3 C, D)$. The ventral stripes are extended rostrally to the zona limitans intrathalamica (ZLI), the boundary between the thalamus and the prethalamus (Puelles and Rubenstein, 2003), whereas the dorsal stripes end in the pretectum (Fig. 3C,D). At this stage, a weaker signal is observed in the lateral ganglionic eminence (LGE), caudal ganglionic eminence (CGE), prethalamus, and olfactory placode (Fig. $3 C, D$ ). At E11.5, the Heslike expression domain is expanded dorsally in the pretectum and the mesencephalon (Fig. 3E). The dorsal expression in the mesencephalon becomes more intense at E12.5 (Fig. $3 F$ ) and is maintained at E13.5 (Fig. 3G). At later stages, the expression in the mesencephalon and the pretectum is gradually downregulated and mostly disappears by E17.5 (data not shown). At E15.5 and later stages, including postnatal stages, Heslike is expressed in the subventricular zone of the ventral telencephalon (Fig. $3 H$ ) and the rostral migratory stream (Fig. 3I, J, arrowheads), which contains precursors for olfactory bulb interneurons. In addition, Heslike is expressed in the vomeronasal organ (Fig. $3 K-M$ ) but 
not in the olfactory epithelium (Fig. 3I). Heslike is not expressed in the regions caudal to the isthmus (data not shown).

To examine Heslike expression in more detail, we generated an antibody $(\mathrm{Ab})$ specific to the Heslike protein and performed immunohistochemistry. This Ab stains the nucleus, and all regions that are reactive to this $\mathrm{Ab}$ express Heslike mRNA (data not shown). Heslike ${ }^{+}$cells are detectable in the ventricular zone of the ventral mesencephalon as early as E9.5 (Fig. 4I, arrowhead) and increase in number at E10.5 (Fig. 4A, B,E,F). All of the Heslike ${ }^{+}$cells coexpress Ki67, an antigen detected in proliferating cells in all phases of the cell cycle (Fig. 4B-D) (Kill, 1996). In addition, some Heslike ${ }^{+}$cells coexpress phosphorylated histone $\mathrm{H} 3$, an $\mathrm{M}$ phase-specific marker (Fig. 4F-H, arrowheads). Thus, Heslike is specifically expressed by proliferating ventricular cells.

To define the Heslike expression domain, we next compared it with the expression of the homeobox factor Nkx2.2. At E9.5, Heslike expression overlaps around the alar-basal boundary with the Nkx2.2 ${ }^{+}$domain (Fig. 4I, arrowhead), which extends from the alar-basal boundary into the ventral region of the mesencephalon. At E10.5, the Nkx2.2 $2^{+}$domain is restricted to the alar-basal boundary re-

gion (Fig. 4J) (Shimamura et al., 1995), whereas Heslike expression is expanded and includes the $\mathrm{Nkx} 2.2^{+}$domain (Fig. $4 J$ ). At approximately E10.5-E11.5, a new $\mathrm{Nkx} 2.2^{+}$domain appears dorsally, and the Heslike ${ }^{+}$domain overlaps with both regions (Fig. $4 K$ ). By E12.5, the Heslike ${ }^{+}$domain is further expanded dorsally, nearly reaching the roof plate, and still overlaps with both Nkx2.2 $2^{+}$domains (Fig. $4 L$ ). However, Heslike expression is mostly absent from the ventral mesencephalon. At E13.5, Heslike expression is downregulated and disappears at E15.5 from the Nkx2.2 ${ }^{+}$domains (data not shown). These results indicate that Heslike is expressed mostly by the mitotic cells of the dorsal mesencephalon.

\section{Coexpression of Heslike and Mash1 in the ventricular zone for GABAergic neurogenesis}

Because Heslike expression domains in the mesencephalon as well as in other regions such as the LGE, prethalamus, rostral migratory stream, and vomeronasal organ are similar to the regions for GABAergic neurogenesis (Wray et al., 1996; Katarova et al., 2000), we next examined the relationship between Heslike expression and markers for GABAergic neurons. We used antibodies to GABA and GAD65, a biosynthetic enzyme for GABA, to detect GABAergic neurons. At E9.5, when Heslike ${ }^{+}$ cells appear (Fig. 5B, arrowhead), there are no GABAergic neurons $\left(\mathrm{GABA}^{+} \mathrm{GAD}^{+} 5^{+}\right)$in the mesencephalon, although neurons $\left(\mathrm{TuJ}_{1}{ }^{+}\right)$are generated (Fig. $\left.5 A, B\right)$. At E10.5, GABAergic neurons are differentiated bilaterally in the mantle layer of the ventral mesencephalon (Fig. 5D, $D^{\prime}, E, E^{\prime}$, green staining), which are located just outside the Heslike ${ }^{+}$domains (Fig. $5 E, E^{\prime}$, red staining). After this stage, as the Heslike ${ }^{+}$domains in the ventricular zone are expanded dorsally, GABAergic neurons
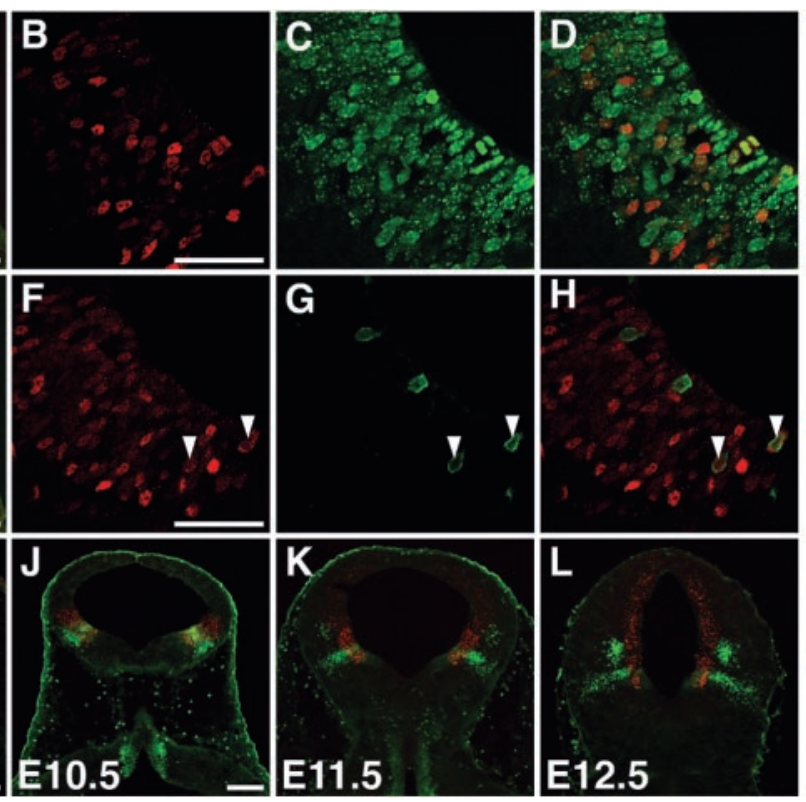

E11.5
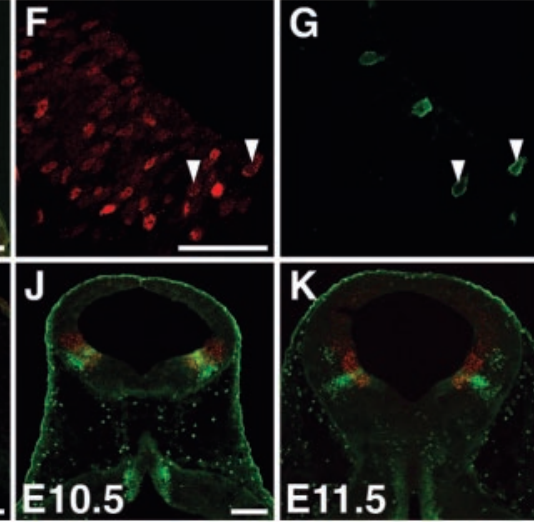

Figure 4. Heslike expression in proliferating cells. $A-H$, Transverse sections of E10.5 mesencephalon. A higher magnification of

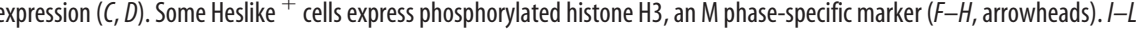
At approximately E10.5-E11.5, a new Nkx2.2 ${ }^{+}$domain appears dorsally, and the Heslike ${ }^{+}$domain overlaps with both regions (K). By E12.5, the Heslike ${ }^{+}$domain is further expanded dorsally, nearly reaching the roof plate $(L)$ and still overlaps with both Nkx2.2 ${ }^{+}$domains. Scale bars: $A, E, I-L, 200 \mu \mathrm{m} ; B-D, F-H, 100 \mu \mathrm{m}$.

also appear dorsally in the mantle layer (Fig. 5G, G', $H$, $\left.H^{\prime}, J, J^{\prime}, K, K^{\prime}\right)$. Thus, expansion of GABAergic neurogenesis follows that of Heslike expression. These results suggest that onset of Heslike expression in ventricular cells induces differentiation of GABAergic neurons.

Because Mash1 is known to regulate differentiation of GABAergic neurons in the telencephalon (Fode et al., 2000), we next examined the relationship between Heslike and Mash1 expression patterns in the mesencephalon. At E9.5, Mash1 expression is observed in two domains: one overlaps with the Heslike ${ }^{+}$ region (Fig. 5C, insets, arrowhead), whereas the other is located in the dorsal mesencephalon (Fig. 5C). At E10.5, when the two Mash $1^{+}$domains are connected, most ventricular cells located in the alar-basal boundary regions coexpress Heslike and Mash1 (Fig. $5 F, F$ ), whereas cells located in the dorsal mesencephalon express Mash1 only (Fig. 5F). At E11.5 and E12.5, as the Heslike ${ }^{+}$region is gradually expanded dorsally, more cells coexpress Heslike and Mash1 (Fig. 5I, I', $L, L^{\prime}$ ). Thus, most of the Heslike $^{+}$cells coexpress Mash1 in the mesencephalon, indicating that $\mathrm{GABA}^{+} \mathrm{GAD} 65^{+}$cells are present in the mantle layer just outside the Heslike ${ }^{+}$Mash1 ${ }^{+}$ventricular zone. These results raise the possibility that coexpression of Heslike and Mash 1 may be involved in formation of GABAergic neurons in the mesencephalon.

We also examined the relationship between Heslike-Mash1 expression and GABAergic neurogenesis in other regions. In the pretectum, GABAergic neurons $\left(\mathrm{GABA}^{+} \mathrm{GAD} 65^{+}\right)$are initially differentiated in two stripes at E10.5 (Fig. $6 A$, arrowheads, $B$ ). Then, at E11.5 and E12.5, GABAergic neurogenesis also occurs in the dorsal region (Fig. 6E, F, I,J). At E10.5, Heslike is expressed in two bilateral stripes, which are next to the initial two stripes of 


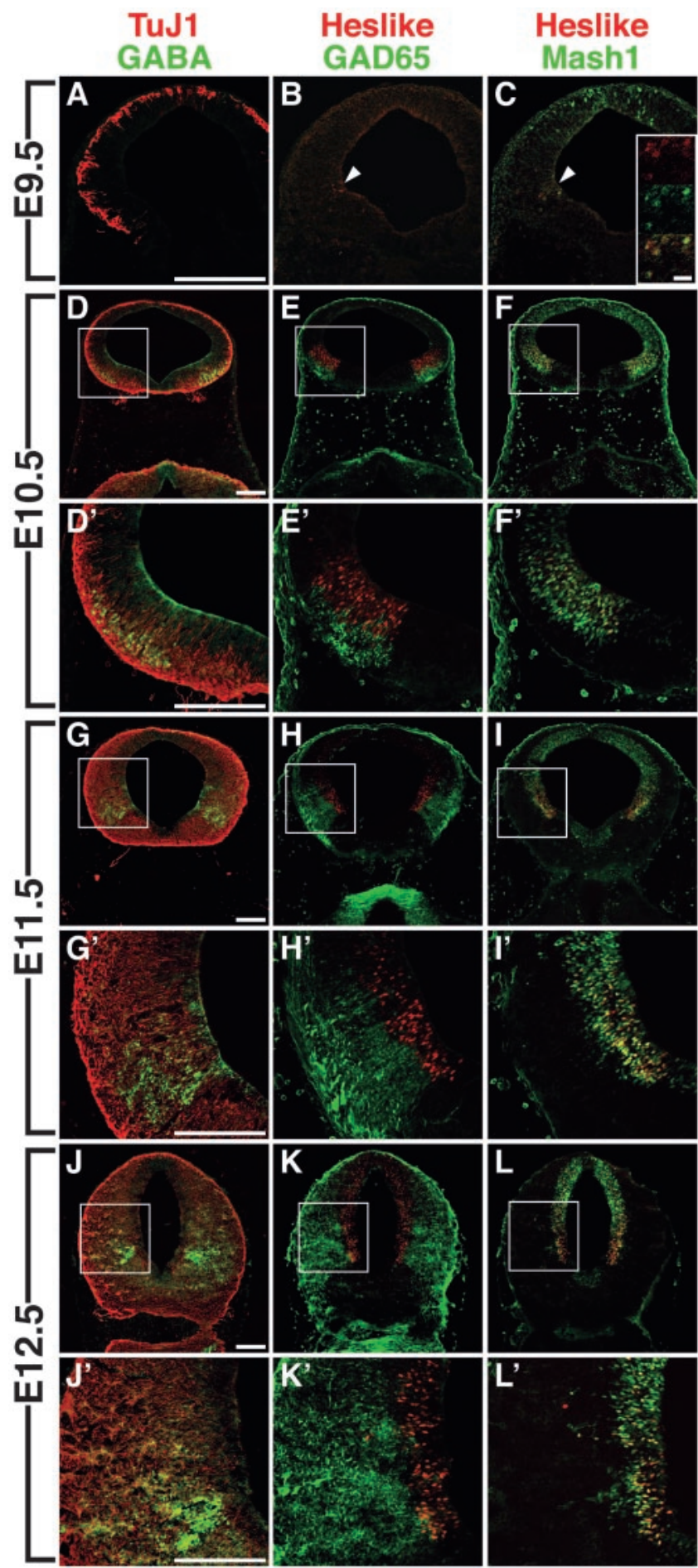

Figure 5. Heslike and Mash1 expression and GABAergic neurogenesis in the mesencephaIon. Transverse sections of the mesencephalon were stained with antibodies. $A-C, A t E 9.5$, GABAergic neurons $\left(\mathrm{GABA}{ }^{+} \mathrm{GAD} 65^{+}\right)$are not yet formed $(A, B)$, although neurons $\left(\mathrm{TuJ1}{ }^{+}\right.$) are differentiated $(A)$. A low level of Heslike expression occurs around the alar-basal boundary ( $B$, arrowhead). Many Heslike ${ }^{+}$cells coexpress Mash1 ( $C$, arrowhead, inset). $D-F, D^{\prime}-F^{\prime}, A t$ E10.5, GABAergic neurons $\left(\mathrm{GABA}{ }^{+}{\mathrm{GAD} 65^{+}}^{+}\right)$are formed in the mantle layer just outside the Heslike ${ }^{+}$ventricular zone $\left(D, D^{\prime}, E, E\right)$. GABA signal is also detected at the ventricular surface of the zone of GABAergic neurons (D). Heslike ${ }^{+}$cells coexpress Mash1 ( $\left.F, F\right) . G-I, G^{\prime}-I^{\prime}$, AtE11.5, the region for GABAergic neuron formation $\left(\mathrm{GABA}{ }^{+} \mathrm{GAD} 65^{+}\right)$is expanded dorsally $\left(G, G^{\prime}, H, H\right)$. This expansion follows dorsal expansion of Heslike ${ }^{+}$domain $(H, H)$. Most Heslike ${ }^{+}$cells coexpress Mash1 $(I, I) . J-L, J^{\prime}-L^{\prime}$, At E12.5, after the dorsal expansion of Heslike ${ }^{+}$ domain, the region for GABAergic neuron formation $\left(\mathrm{GABA}{ }^{+} \mathrm{GAD} 65^{+}\right)$is further expanded dorsally $\left(J, J^{\prime}, K, K^{\prime}\right)$. Most Heslike ${ }^{+}$cells coexpress Mash1 $(L, L)$. A higher magnification of the indicated region in $D-L$ is shown in $D^{\prime}-L^{\prime}$, respectively. Scale bars, $200 \mu \mathrm{m}$.
GABAergic neurons (Fig. 6B). At this stage, Mash1 is widely expressed in the dorsal two thirds, which include the two stripes of Heslike $^{+}$domains (Fig. $6 C$ ). The dorsal stripe of the Heslike ${ }^{+}$ domain is expanded dorsally at E11.5 (Fig. $6 \mathrm{~F}-\mathrm{H}$ ) and at E12.5 (Fig. $6 J-L$ ), whereas the ventral stripe does not show much change (Fig. $6 F-H, J-L$ ). During these stages, Heslike is coexpressed with Mash1 in the two bilateral stripes (Fig. 6G,K). Strikingly, there are many GAD $65^{+}$cells in the mantle layer just outside the Heslike ${ }^{+}$Mash1 ${ }^{+}$ventricular zone (Fig. 6F,J). Thus, coexpression of Heslike and Mash1 correlates well to GABAergic neurogenesis in this region. We also compared expression of Heslike with that of Nkx2.2, which occurs in the alar-basal boundary region. During E10.5-E12.5, the ventral stripe of the Heslike ${ }^{+}$ domain overlaps with $\mathrm{Nkx} 2.2$ expression, but Heslike is not expressed ventrally to the Nkx2.2 ${ }^{+}$domain (Fig. $6 D, H, L$ ), indicating that Heslike is not expressed in the basal plate.

Heslike is also highly expressed by the cells located in a stripe caudal to the ZLI, which expresses Shh (Fig. 6P). These cells coexpress Mash1 (Fig. 6N,O, arrow), and there are many GABAergic neurons $\left(\mathrm{GAD} 5^{+}\right)$outside this Heslike ${ }^{+}$Mash $1^{+}$ stripe (Fig. $6 \mathrm{M}$ ). Altogether, these results indicate that coexpression of Heslike and Mash1 correlates well to GABAergic neurogenesis in the mesencephalon and the caudal diencephalon.

In the region rostral to the ZLI, subsets of ventricular cells in the prethalamus, LGE, CGE, and preoptic area coexpress Heslike and Mash1, but none of the cells in the MGE do (data not shown). Although GABAergic neurons are generated in the mantle layer just outside the Heslike ${ }^{+}$Mash $1^{+}$regions, the number of Heslike $^{+}$cells is much fewer in these regions than that of GABAergic neurons, suggesting that Heslike may be involved in differentiation of only subsets of GABAergic neurons in this area (data not shown).

\section{Heslike induces GABAergic neurogenesis from \\ Mash $1^{+}$region}

To characterize the function of Heslike, we generated transgenic mice misexpressing Heslike from the nestin promoter-enhancer. This promoter-enhancer induces Heslike expression widely in the ventricular zone (Fig. $7 \mathrm{~B}, J$ ), as described previously (Zimmerman et al., 1994; Isaka et al., 1999). Because these mice typically die by E12.5, we examined founder embryos of E10.5 and E11.5 $(n=5)$. In the mesencephalon, misexpression of Heslike induces ectopic GABAergic neurons in the regions both ventral and dorsal to the original $\mathrm{GAD}^{+} 5^{+}$domains at E10.5 (Fig. 7, compare $A$ and $B$ ). The dorsal mesencephalon, which normally expresses only Mash1 (Fig. $7 E$ ) and does not yet give rise to any GABAergic neurons at E10.5 (Fig. 7A), prematurely generates GAD $65^{+}$cells by misexpression of Heslike (Fig. 7C; some ectopic GAD $65^{+}$cells are indicated by arrowheads). Similarly, the region just ventral to the original GAD $65^{+}$domain that normally expresses Mash 1 only and does not give rise to GABAergic neurons at any stages generates ectopic GABAergic neurons by misexpression of Heslike (Fig. 7D, arrowheads). In these regions, Mash1 is also expressed (Fig. $7 \mathrm{~F}-\mathrm{H}$ ).

In a different transgenic embryo, Heslike is ectopically expressed by subsets of ventricular cells of the mesencephalon and the caudal diencephalon at E11.5 (Fig. 7, compare $J$ and $N$ with $I$ and $M)$. In these mice, ectopic GABAergic neurons are generated in the regions both ventral and dorsal to the original GAD65 domains (Fig. $7 \mathrm{~J}, N$ ). Again, the dorsal region, which normally expresses only Mash1 (Fig. 5I) and does not yet give rise to any GABAergic neurons at E11.5 (Fig. 7I), prematurely generates $\mathrm{GAD} 5^{+}$cells by misexpression of Heslike (Fig. $7 \mathrm{~K}, \mathrm{~L}$, arrow- 
heads). Similarly, the region just ventral to the original GAD65 ${ }^{+}$domain that normally expresses Mash1 only and does not give rise to GABAergic neurons at any stages generates ectopic GABAergic neurons by misexpression of Heslike (Fig. $7 O, P$, arrowheads). Ectopic GABAergic neurons are present only in the mantle layer just outside the Heslike ${ }^{+} \mathrm{Mash}^{+}{ }^{+}$region (Fig. $7 L, P$, arrowheads), suggesting that Heslike ${ }^{+}$Mash $1^{+}$cells radially migrate and become GABAergic neurons. In contrast, misexpression of Heslike in the dorsal telencephalon and the thalamus, which do not express Mash1 (Fig. 7Q,R), does not generate ectopic GABAergic neurons by misexpression of Heslike (Fig. 7S,T, arrowheads). These results indicate that Heslike specifies the GABAergic neuronal fate only when Mash1 is co-expressed.

We did not observe a clear increase in the number of GABAergic neurons in the region rostral to the ZLI associated with misexpression of Heslike, although Mash1 is expressed (data not shown). These results suggest that the mechanism for GABAergic neurogenesis may be different between the regions rostral and caudal to the ZLI.

\section{Loss of GABAergic neurons in the absence of Mash1}

Because Heslike does not induce ectopic GABAergic neurons in the Mash1negative region, we next examined the requirement of Mash1 for GABAergic neurogenesis. It was previously shown that in the absence of Mash1, although neuronal precursors are severely lost, GABAergic neurons are generated in the ventral telencephalon, suggesting that Mash1 is dispensable for GABAergic neurogenesis in the telencephalon (Casarosa et al., 1999). We thus examined other regions of Mash1-null mice. In the region between the ZLI and the isthmus of Mash1-null mice, only a very few GABAergic neurons $\left(\mathrm{GABA}^{+} \mathrm{GAD}^{+}{ }^{+}\right.$) are differentiated (Fig. 8 , compare $D, D^{\prime}, F$, and $F^{\prime}$ with $C, C^{\prime}, E$, and $E^{\prime}$, respectively), even though more ventricular cells seem to express Heslike in Mash1-null mice (Fig. 8, compare $B$ and $B$ ' with $A$ and $A^{\prime}$ '). Thus, Heslike alone is not sufficient, but Mash1 is required for generation of most GABAergic neurons in this region. Because neurons $\left(\mathrm{TuJ} 1^{+}\right)$are generated throughout Mash1-null mesencephalon (Fig. $8 F, F^{\prime}$ ) and caudal diencephalon (data not shown), it is possible that, instead of GABAergic neurons, different subtypes of neurons are generated. These results indicate that Heslike and Mash1 cooperatively specify GABAergic neurons in the region between the ZLI and the isthmus, whereas either factor alone is not sufficient for such specification.
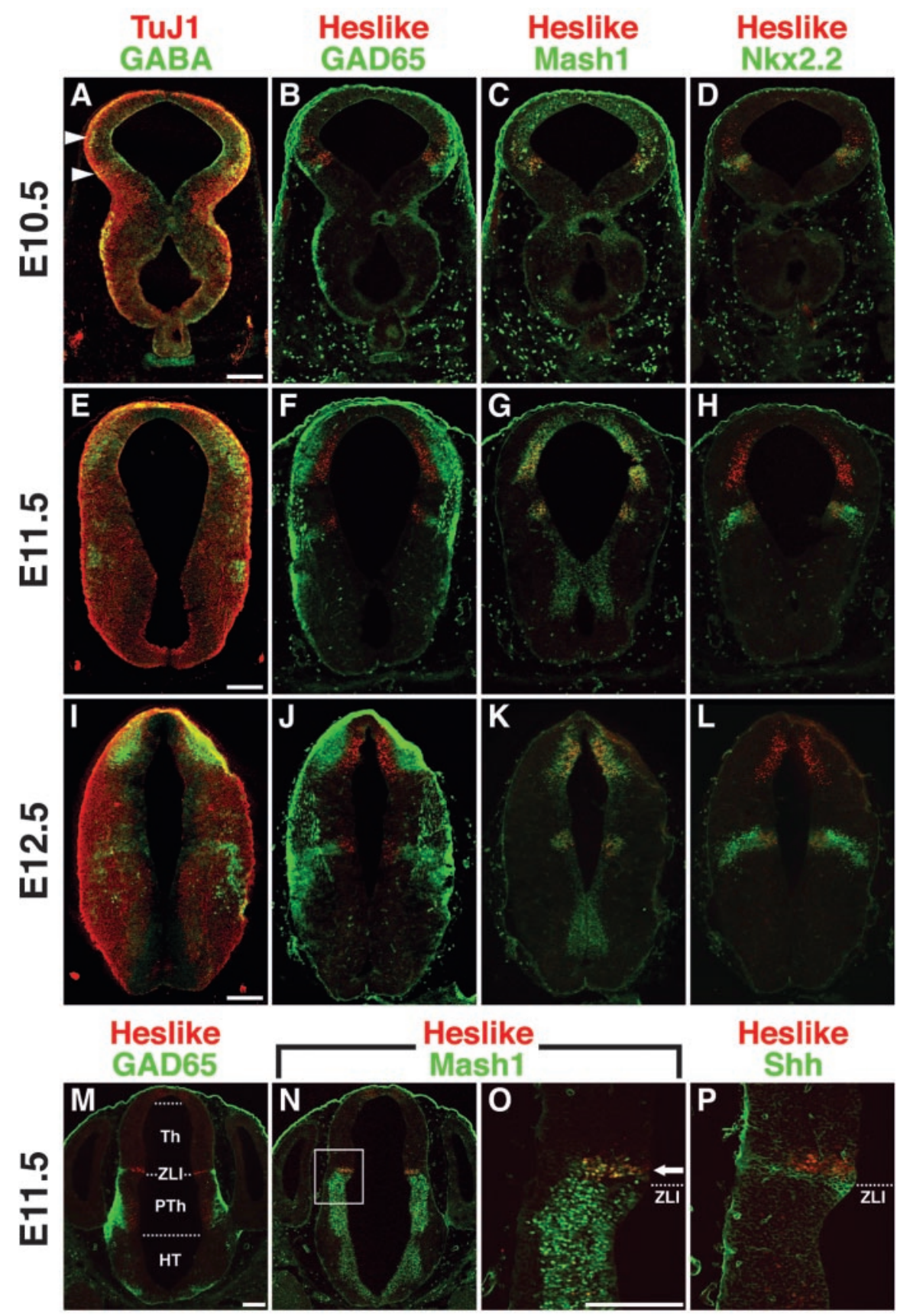

Heslike

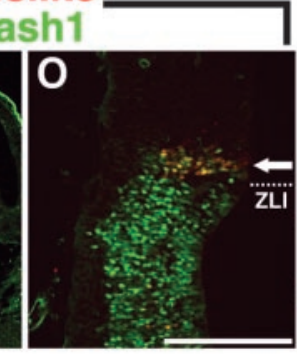

Heslike Shh

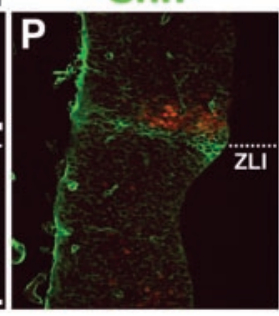

Figure 6. Heslike and Mash1 expression and GABAergic neurogenesis in the diencephalon. Transverse sections were stained with antibodies. $A-D, A t E 10.5, \mathrm{GABAergic}$ neurons $\left(\mathrm{GABA}{ }^{+} \mathrm{GAD} 65^{+}\right)$are formed in the mantle layer just outside the two stripes of Heslike ${ }^{+}$ventricular regions in the pretectum (PT) $\left(A\right.$, arrowheads, $B$ ). Neurons (TuJ1 $\left.{ }^{+}\right)$are differentiated widely in the diencephalon (A). Most Heslike ${ }^{+}$cells coexpress Mash1 (C). Heslike ${ }^{+}$regions overlap with Nkx2.2 expression domains (D).E-L, At E11.5 and E12.5, the dorsal stripe of Heslike ${ }^{+}$ventricular region is expanded dorsally, and GABAergic neurons $\left(\mathrm{GABA}^{+} \mathrm{GAD}^{+} 5^{+}\right.$) are formed in the mantle layer just outside the Heslike ${ }^{+}$ventricular zone $(E, F, I, J)$. Most Heslike ${ }^{+}$cells coexpress Mash1 $(G, K)$, and some regions overlap with Nkx2.2 domains $(H, L)$. M-P, At E11.5, there are $\mathrm{GAD}^{+} 5^{+}$cells just outside the Heslike ${ }^{+}$region near the ZLI $(M)$. Heslike is coexpressed with Mash1 ( $O$, arrow) in a stripe just caudal to the $Z \mathrm{ZI}$, which expresses Shh $(P)$. A higher magnification of the indicated region in $N$ is shown in 0 . Scale bars, $200 \mu \mathrm{m}$. 

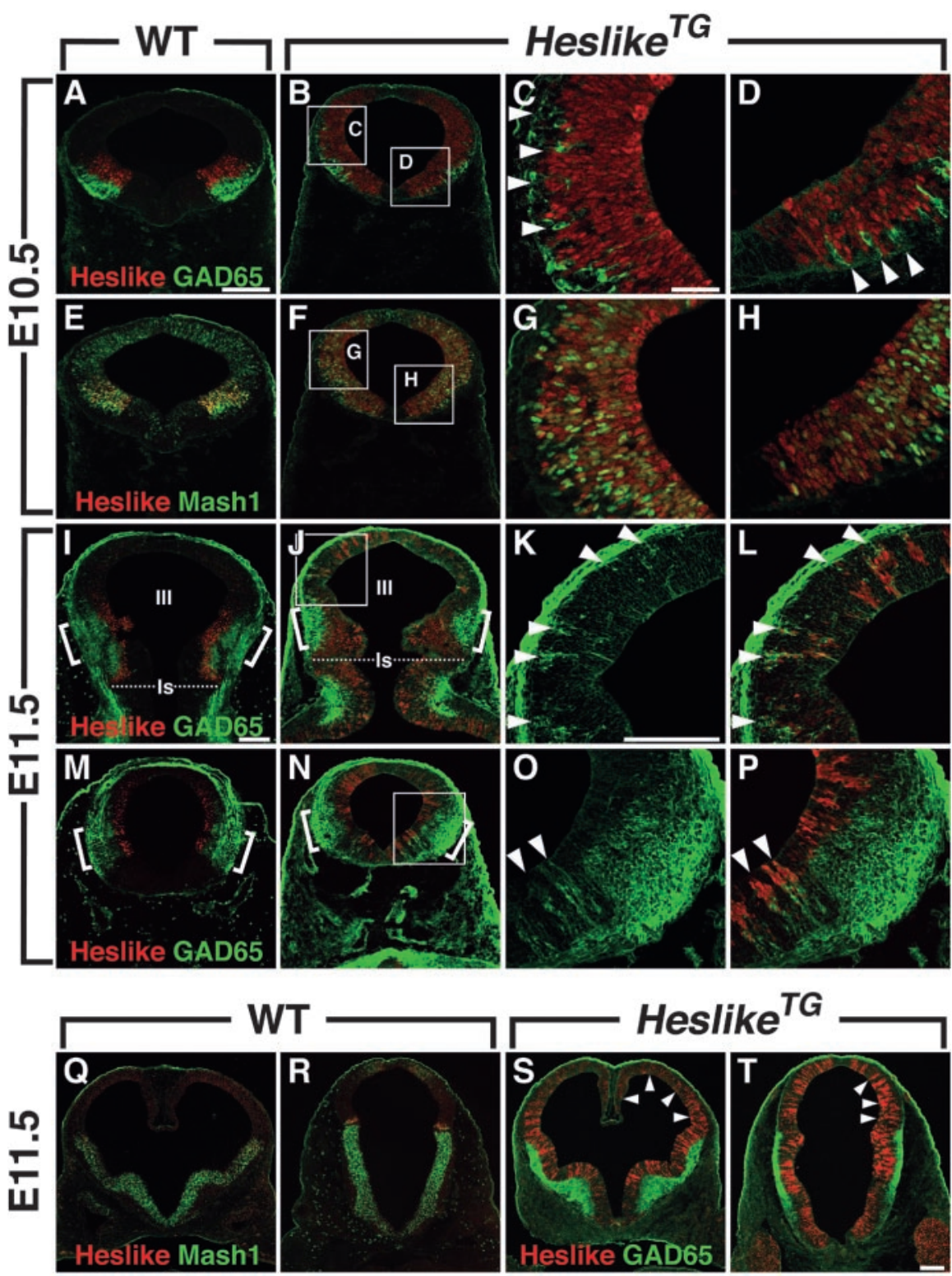

Figure 7. Promotion of GABAergic neurogenesis in mice misexpressing Heslike. $A-T$, Transgenic mice misexpressing Heslike from the nestin promoter-enhancer $(B-D, F-H, J-L, N-P, S, T)$ and wild-type mice $(A, E, I, M, Q, R)$ were analyzed at E10.5 and E11.5 by immunohistochemistry. $B-D, F-H$, In this transgenic embryo, Heslike is widely expressed in the mesencephalon. Many $G A B A e r g i c$ neurons are ectopically formed in the regions both ventral and dorsal to the original $G A D 65^{+}$region $(B-D$, arrowheads, compare with $A$ ). In these regions, Mash1 is coexpressed $(G, H)$. J-L, N-P, In this transgenic embryo, Heslike is misexpressed in the mesencephalon $(J-L)$ and the caudal diencephalon $(N-P)$. In the dorsal region, which normally expresses only Mash1 at this stage, misexpression of Heslike prematurely generates GABAergic neurons ( $K, L$, arrowheads). In the ventral region, which normally expresses Mash1 only and does not give rise to GABAergic neurons at any stages, misexpression of Heslike ectopically generates $\mathrm{GABAergic}$ neurons $\left(\mathrm{GAD} 5^{+}\right)\left(0, P\right.$, arrowheads). The original $\mathrm{GAD} 65^{+}$domains are indicated by brackets $(I, J, M, N) . Q-T$, In the dorsal telencephalon $(Q)$ and the thalamus $(R)$, Mash1 is not expressed. In these regions, misexpression of Heslike does not generate ectopic GABAergic neurons (S,T, arrowheads). Scale bars: A, B, E, F, I-T, $200 \mu \mathrm{m} ; C, D, G, H, 50 \mu \mathrm{m}$.

suggesting that in other regions, as yet unidentified factors may be involved in generation of GABAergic neurons.

Co-expression of Heslike and Mash1 increases the population of GABAergic neurons in neural precursor cell culture

To examine the cooperative activities of Heslike and Mash1 in GABAergic neurogenesis, we performed neural precursor cell culture. The expression vectors for Heslike and Mash1 were transfected into E11.5 embryonal telencephalon, and neural precursor cells were prepared from the transfected brains. Coexpres- sion of Heslike and Mash1 significantly increases the number of GABAergic neurons (Fig. 9A,B), compared with expression of Heslike or Mash1 alone (Fig. 9B). These results support the notion that Heslike and Mash 1 cooperatively specify the GABAergic neuronal fate.

\section{Discussion}

Heslike, together with Mash1, specifies the GABAergic neuronal fate

Here, we identified a novel bHLH factor, termed Heslike, which is coexpressed with Mash1 by mitotic cells in the ventricular zone of many brain regions. At E9.5, Heslike and Mash1 are coexpressed in the ventral mesencephalon and then this coexpression is expanded to other regions. Strikingly, many GABAergic neurons are formed in the mantle layer just outside the Mash $1^{+}$ventricular zone after Heslike is coexpressed. GABAergic neurogenesis in the region between the ZLI and the isthmus always follows coexpression of Heslike and Mash1, indicating that Heslike and Mash 1 cooperatively promote GABAergic neurogenesis. It is likely that Heslike regulates the timing of GABAergic neuronal differentiation from Mash1 cells.

Immunohistochemical analysis does not show any coexpression of Heslike and GAD65-GABA because Heslike is expressed by proliferating cells, whereas GAD65 and GABA are expressed by postmitotic cells. Thus, it remains to be determined whether Heslike ${ }^{+}$Mash ${ }^{+}$cells really differentiate into GABAergic neurons. However, previous studies demonstrated that, unlike in the telencephalon, the majority of the ventricular cells in the mesencephalon migrate radially (Tan et al., 2002). Thus, it is most likely that the Heslike ${ }^{+} \mathrm{Mash}^{+}{ }^{+}$ventricular cells differentiate into GABAergic neurons. Consistent with this notion, misexpression of Heslike in the Mash ${ }^{+}$region generates ectopic GABAergic neurons in the mantle layer just outside the Heslike ${ }^{+}$Mash1 ventricular zone in the mesencephalon and the caudal diencephalon.

In Mash1-null mice, GABAergic neurons are primarily missing in the region between the ZLI and the isthmus, although Heslike is still expressed. In these mutants, $\mathrm{TuJ1}{ }^{+}$neurons are differentiated, suggesting that different subtypes of neurons are generated when Mash1 is absent and only Heslike is expressed. Similarly, when only Mash 1 is expressed, there are no GABAergic neurons in the region between the ZLI and the isthmus, although $\mathrm{TuJ}^{+}$neurons are differentiated, suggesting that different subtypes of neurons are generated when Heslike is absent and only Mash1 is expressed. Thus, Heslike or Mash1 alone is not sufficient, but their coexpression may be required for GABAergic 
neurogenesis. However, it is also possible that in Mash1-null mice, GABAergic neurons are simply eliminated because of loss of the proneural activity of Mash1 rather than mis-specified. In this case, nonGABAergic neurons could be differentiated from distinct precursors, which depend on other proneural genes such as Ngn1 (Ma et al., 1997). Whatever the case, combination of Heslike and Mash1 is important for GABAergic neurogenesis, because misexpression of Heslike does not induce GABAergic neurons in the regions that do not express Mash1.

The results shown above suggest that the caudal diencephalon and the mesencephalon may use different strategies from the telencephalon to generate neuronal subtype diversity. In the telencephalon, GABAergic neurons are generated ventrally and migrate tangentially to the dorsal telencephalon, indicating that neuronal migration contributes to the neuronal diversity of the dorsal telencephalon. In contrast, in the caudal diencephalon and the mesencephalon, the ventricular cells change their expression profile of bHLH factors over time and gain competency to produce GABAergic neurons, thereby increasing neuronal diversity.

\section{Co-expression of Heslike and Mash1 may be involved in GABAergic neurogenesis in other regions}

Although GABAergic neurons are virtually missing in the region between the ZLI and the isthmus of Mash1-null mice, they are generated in other regions (rostral to the ZLI and caudal to the isthmus), suggesting that GABAergic neurogenesis depends on different transcription factors in such regions. In the ventral telencephalon, homeodomain factors such as $\mathrm{Nkx} 2.1$ and Dlx1/2 are involved in GABAergic neurogenesis (Anderson et al., 1997a,b; Casarosa et al., 1999; Sussel et al., 1999; Marín et al., 2000). These homeodomain factors are not expressed in other regions. In the region caudal to the isthmus, Heslike is not expressed, and other homeodomain factors are essential for GABAergic neurogenesis (Jessell, 2000; Caspary and Anderson, 2003). These results suggest that the three regions rostral to the ZLI, between the ZLI and the isthmus, and caudal to the isthmus use different transcription factor sets for GABAergic neurogenesis.

Although Heslike may not be an essential factor for GABAergic neurogenesis in the region rostral to the ZLI, it is always coexpressed with Mash1 in this region by the ventricular cells that give rise to GABAergic neurons. The number of those Heslike ${ }^{+}$Mash ${ }^{+}$cells is much smaller compared with the extensive number of GABAergic neurons in this area. Thus, although Heslike is not required for generation of the majority of GABAegic neurons, it could be involved in differentiation of subsets of GABAergic neurons in the region rostral to the ZLI. Consistent with this notion, we found that coexpression of Heslike and Mash1 in neural precursor cells of the telencephalon promotes generation of GABAergic neurons.

\section{Combinations of distinct transcription factors increase the repertoire of neuronal subtypes}

It has been shown that combinations of bHLH and homeodomain factors specify neuronal subtypes. For example, in the retina, a combination of the bHLH factor Math3 and the homeodomain factor Chx10 generates bipolar neurons (Hatakeyama et al., 2001), whereas a combination of Math3 and the homeodomain factor Pax6 generates amacrine and horizontal neurons (Inoue et al., 2002). Thus, Math3 promotes specification of distinct neuronal subtypes depending on the combinatorial partners. The precise mechanism for this combinatorial action between bHLH and homeodomain factors is not known, but it was reported that some bHLH and homeodomain factors physically interact with each other. The bHLH factor Pan 1 and the homeodomain factor Pitx1 form a complex through the bHLH domain and the homeodomain and synergistically induce gene expression (Poulin et al., 2000). It was also reported that functional coupling of bHLH and homeodomain factors is mediated by an adaptor protein (Lee and Pfaff, 2003).

The mechanism for combinatorial actions of Heslike and Mash1 also remains to be determined. One most likely mechanism is that Heslike and Mash1 may form a heterodimer complex through the bHLH domain and bind to a DNA sequence distinct from those recognized by their homodimers or heterodimers with the ubiquitous bHLH cofactor E47. Our results suggest that combinations of distinct bHLH factors promote formation of distinct neuronal subtypes. Similarly, coexpression of Ngn2 and Olig2 promotes somatic motor neuron formation, whereas each factor alone induces distinct cell types. Thus, a combinatorial action of distinct bHLH factors seems to be a general mechanism to increase the cell type diversity. 
A

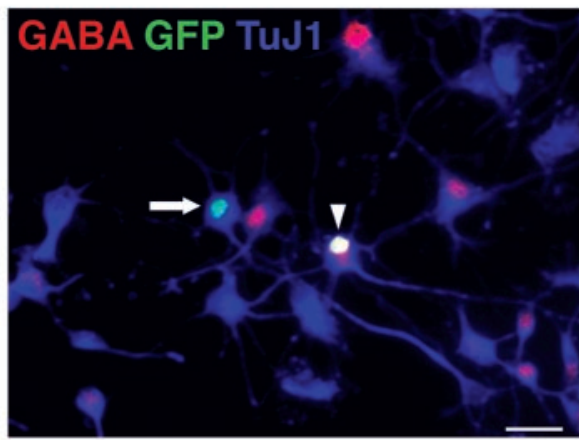

B

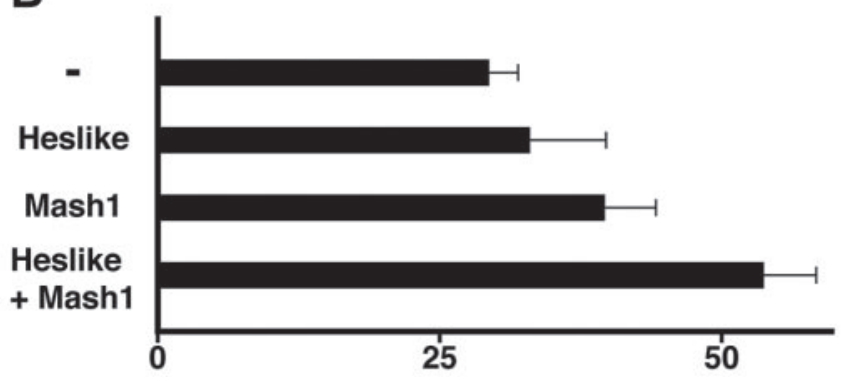

GABAergic neuron / $\mathrm{GFP}^{+}$cell (\%)

Figure 9. Promotion of GABAergic neurogenesis in neural precursor cell culture by coexpression of Heslike and Mash1. A, The expression vectors for Heslike and Mash1 were cotransfected into neural precursor cells. There are two transfected cells (GFP $\left.{ }^{+}\right)$in this panel. One becomes a GABAergic neuron (arrowhead; $\mathrm{GABA}^{+} \mathrm{TuJ}^{+}$), whereas the other is a non-GABAergic neuron (arrow; GABA ${ }^{-} \mathrm{TuJ}^{+}{ }^{+}$). Scale bar, $20 \mu \mathrm{m}$. B, Quantification of GABAergic neurons. Ratios of GABAergic neurons $\left(\mathrm{GABA}^{+}\right)$per transfected cells $\left(\mathrm{GFP}^{+}\right)$are calculated. Each value with an SE represents four independent experiments performed in duplicate. Coexpression of Heslike and Mash1 promotes generation of GABAergic neurons.

\section{Similarities and differences between Heslike and Hes1}

Although Heslike has a high sequence homology in the bHLH domain to Hes1, there are some structural differences between the two. The proline residue in the middle of the basic region conserved among all Hes factors is not present in Heslike. Furthermore, the carboxy-terminal WRPW sequence conserved among all Hes factors is not present in Heslike. In addition to the structural differences, Heslike is also functionally different from Hes1, although both act as N box-dependent transcriptional repressors. Hes1 is widely expressed in the developing nervous system and has been shown to inhibit neuronal differentiation and maintain neural stem cells (Ishibashi et al., 1994; Ohtsuka et al., 1999, 2001; Nakamura et al., 2000). Transient misexpression of Hes1 delays differentiation of neural stem cells and increases the number of late born cell types such as cortical neurons in the superficial layers and astrocytes (Ohtsuka et al., 2001). In contrast, transient misexpression of Heslike increases the number of GABAergic neurons when Mash1 is coexpressed. Thus, Heslike constitutes a subfamily that is structurally and functionally different from Hes factors.

Despite the functional difference as stated above, we found that misexpression of Heslike in the developing cortex inhibits neurogenesis, as does Hes1 (our unpublished data). In addition, Heslike is expressed only by proliferating ventricular cells, like Hes1. Thus, it is possible that Heslike, like Hes1, may also function as a negative regulator for neuronal differentiation in addition to specifying the GABAergic fate. Consistent with this no- tion, the number of ectopic GABAergic neurons induced by misexpression of Heslike is relatively small. We thus speculate that, although Heslike endows ventricular cells with the GABAergic fate, downregulation of Heslike expression is required for maturation of GABAergic neurons. Additional analysis of Heslike will reveal the mechanism for specification of the GABAergic neuronal fate and the combinatorial actions of bHLH factors.

\section{References}

Anderson SA, Eisenstat DD, Shi L, Rubenstein JLR (1997a) Interneuron migration from basal forebrain to neocortex: dependence on $D l x$ genes. Science 278:474-476.

Anderson SA, Qiu M, Bulfone A, Eisenstat DD, Meneses J, Pedersen R, Rubenstein JLR (1997b) Mutations of the homeobox genes Dlx-1 and Dlx-2 disrupt the striatal subventricular zone and differentiation of late born striatal neurons. Neuron 19:27-37.

Bertrand N, Castro DS, Guillemot F (2002) Proneural genes and the specification of neural cell types. Nat Rev Neurosci 3:517-530.

Casarosa S, Fode C, Guillemot F (1999) Mash1 regulates neurogenesis in the ventral telencephalon. Development 126:525-534.

Caspary T, Anderson KV (2003) Patterning cell types in the dorsal spinal cord: what the mouse mutants say. Nat Rev Neurosci 4:289-297.

Chin MT, Maemura K, Fukumoto S, Jain MK, Layne MD, Watanabe M, Hsieh C-M, Lee M-E (2000) Cardiovascular basic helix-loop-helix factor 1 , a novel transcriptional repressor expressed preferentially in the developing and adult cardiovascular system. J Biol Chem 275:6381-6387.

Corbin JG, Gaiano N, Machold RP, Langston A, Fishell G (2000) The Gsh2 homeodomain gene controls multiple aspects of telencephalic development. Development 127:5007-5020.

Corbin JG, Nery S, Fishell G (2001) Telencephalic cells take a tangent: nonradial migration in the mammalian forebrain. Nat Neurosci 4:1177-1182.

Davis RL, Cheng P-F, Lassar AB, Weintraub H (1990) The MyoD DNA binding domain contains a recognition code for muscle-specific gene activation. Cell 60:733-746.

De Carlos JA, López-Mascaraque L, Valverde F (1996) Dynamics of cell migration from the lateral ganglionic eminence in the rat. J Neurosci 16:6146-6156.

Fode C, Ma Q, Casarosa S, Ang S-L, Anderson DJ, Guillemot F (2000) A role for neural determination genes in specifying the dorsoventral identity of telencephalic neurons. Genes Dev 14:67-80.

Grbavec D, Stifani S (1996) Molecular interaction between TLE1 and the carboxyl-terminal domain of HES-1 containing the WRPW motif. Biochem Biophys Res Commun 223:701-705.

Guillemot F, Lo L-C, Johnson JE, Auerbach A, Anderson DJ, Joyner AL (1993) Mammalian achaete-scute homolog 1 is required for the early development of olfactory and autonomic neurons. Cell 75:463-476.

Hatakeyama J, Tomita K, Inoue T, Kageyama R (2001) Roles of homeobox and bHLH genes in specification of a retinal cell type. Development 128:1313-1322.

Hirata H, Ohtsuka T, Bessho Y, Kageyama R (2000) Generation of structurally and functionally distinct factors from the basic helix-loop-helix gene Hes3 by alternative first exons. J Biol Chem 275:19083-19089.

Hirata H, Tomita K, Bessho Y, Kageyama R (2001) Hes1 and Hes3 regulate maintenance of the isthmic organizer and development of the $\mathrm{mid} / \mathrm{hind}$ brain. EMBO J 20:4454-4466.

Inoue T, Hojo M, Bessho Y, Tano Y, Lee JE, Kageyama R (2002) Math3 and NeuroD regulate amacrine cell fate specification in the retina. Development 129:831-842.

Isaka F, Ishibashi M, Taki W, Hashimoto N, Nakanishi S, Kageyama R (1999) Ectopic expression of the bHLH gene Math1 disturbs neural development. Eur J Neurosci 11:2582-2588.

Ishibashi M, Moriyoshi K, Sasai Y, Shiota K, Nakanishi S, Kageyama R (1994) Persistent expression of helix-loop-helix factor HES-1 prevents mammalian neural differentiation in the central nervous system. EMBO J 13:1799-1805.

Iso T, Sartorelli V, Chung G, Shichinohe T, Kedes L, Hamamori Y (2001) HERP, a new primary target of Notch regulated by ligand binding. Mol Cell Biol 21:6071-6079.

Jessell TM (2000) Neuronal specification in the spinal cord: inductive signals and transcriptional codes. Nat Rev Genet 1:20-29.

Katarova Z, Sekerková G, Prodan S, Mugnaini E, Szabó G (2000) Domain- 
restricted expression of two glutamic acid decarboxylase genes in midgestation mouse embryos. J Comp Neurol 424:607-627.

Kill I (1996) Localisation of the Ki-67 antigen within the nucleolus. J Cell Sci 109:1253-1263.

Kokubo H, Lun Y, Johnson RL (1999) Identification and expression of a novel family of bHLH cDNAs related to Drosophila Hairy and Enhancer of split. Biochem Biophys Res Commun 260:459-465.

Lee S-K, Pfaff SL (2003) Synchronization of neurogenesis and motor neuron specification by direct coupling of bHLH and homeodomain transcription factors. Neuron 38:731-745.

Leimeister C, Externbrink A, Klamt B, Gessler M (1999) Hey genes: a novel subfamily of hairy- and Enhancer of split related genes specifically expressed during mouse embryogenesis. Mech Dev 85:173-177.

Lu QR, Cai L, Rowitch D, Cepko CL, Stiles CD (2001) Ectopic expression of Olig1 promotes oligodendrocyte formation and reduces neuronal survival in developing mouse cortex. Nat Neurosci 4:973-974.

Lu QR, Sun T, Zhu Z, Ma N, Garcia M, Stiles CD, Rowitch DH (2002) Common developmental requirement for Olig function indicates a motor neuron/oligodendrocyte connection. Cell 109:75-86.

Ma Q, Sommer L, Cserjesi P, Anderson DJ (1997) Mash1 and neurogenin1 expression patterns define complementary domains of neuroepithelium in the developing CNS and are correlated with regions expressing Notch ligands. J Neurosci 17:3644-3652.

Marín O, Anderson SA, Rubenstein JLR (2000) Origin and molecular specification of striatal interneurons. J Neurosci 20:6063-6076.

Mizuguchi R, Sugimori M, Takebayashi H, Kosako H, Nagao M, Yoshida S, Nabeshima Y, Shimamura K, Nakafuku M (2001) Combinatorial roles of Olig2 and Neurogenin2 in the coordinated induction of pan-neuronal and subtype-specific properties of motoneurons. Neuron 31:757-771.

Murray RC, Navi D, Fesenko J, Lander AD, Calof AL (2003) Widespread defects in the primary olfactory pathway caused by loss of Mash 1 function. J Neurosci 23:1769-1780.

Nakagawa O, Nakagawa M, Richardson JA, Olson EN, Srivastava D (1999) HRT1, HRT2, and HRT3: a new subclass of bHLH transcription factors marking specific cardiac, somitic, and pharyngeal arch segments. Dev Biol 216:72-84.

Nakamura Y, Sakakibara S, Miyata T, Ogawa M, Shimazaki T, Weiss S, Kageyama R, Okano H (2000) The bHLH gene Hes1 as a repressor of the neuronal commitment of CNS stem cells. J Neurosci 20:283-293.

Nieto M, Schuurmans S, Britz O, Guillemot F (2001) Neural bHLH genes control the neuronal versus glial fate decision in cortical progenitors. Neuron 29:401-413.

Novitch BG, Chen AI, Jessell TM (2001) Coordinate regulation of motor neuron subtype identity and pan-neuronal properties by the bHLH repressor Olig2. Neuron 31:773-789.

Ohtsuka T, Ishibashi M, Gradwohl G, Nakanishi S, Guillemot F, Kageyama R (1999) Hes 1 and Hes5 as Notch effectors in mammalian neuronal differentiation. EMBO J 18:2196-2207.

Ohtsuka T, Sakamoto M, Guillemot F, Kageyama R (2001) Roles of the basic helix-loop-helix genes Hes1 and Hes5 in expansion of neural stem cells of the developing brain. J Biol Chem 276:30467-30474.

Paroush Z, Finley Jr RL, Kidd T, Wainwright SM, Ingham PW, Brent R, Ish-Horowictz D (1994) Groucho is required for Drosophila neurogenesis, segmentation, and sex determination and interacts directly with hairy-related bHLH proteins. Cell 79:805-815.

Parras CM, Schuurmans C, Scardigli R, Kim J, Anderson DJ, Guillemot F
(2002) Divergent functions of the proneural genes Mash1 and Ngn2 in the specification of neuronal subtype identity. Genes Dev 16:324-338.

Poulin G, Lebel M, Chamberland M, Paradis FW, Drouin J (2000) Specific protein-protein interaction between basic helix-loop-helix transcription factors and homeoproteins of the Pitx family. Mol Cell Biol 20:4826-4837.

Puelles L, Rubenstein JLR (2003) Forebrain gene expression domains and the evolving prosomeric model. Trends Neurosci 26:469-476.

Ross SE, Greenberg ME, Stiles CD (2003) Basic helix-loop-helix factors in cortical development. Neuron 39:13-25.

Sasai Y, Kageyama R, Tagawa Y, Shigemoto R, Nakanishi S (1992) Two mammalian helix-loop-helix factors structurally related to Drosophila hairy and Enhancer of split. Genes Dev 6:2620-2634.

Shimamura K, Hartigan DJ, Martinez S, Puelles L, Rubenstein JLR (1995) Longitudinal organization of the anterior neural plate and neural tube. Development 121:3923-3933.

Sun Y, Nadal-Vicens M, Misono S, Lin MZ, Zubiaga A, Hua X, Fan G, Greenberg ME (2001) Neurogenin promotes neurogenesis and inhibits glial differentiation by independent mechanisms. Cell 104:365-376.

Sussel L, Marin O, Kimura S, Rubenstein JLR (1999) Loss of Nkx2.1 homeobox gene function results in a ventral to dorsal molecular respecification within the basal telencephalon: evidence for a transformation of the pallidum into the striatum. Development 126:3359-3370.

Tamamaki N, Fujimori KE, Takauji R (1997) Origin and route of tangentially migrating neurons in the developing neocortical intermediate zone. J Neurosci 17:8313-8323.

Tan S-S, Valcanis H, Kalloniatis M, Harvey A (2002) Cellular dispersion patterns and phenotypes in the developing mouse superior colliculus. Dev Biol 241:117-131.

Tomita K, Moriyoshi K, Nakanishi S, Guillemot F, Kageyama R (2000) Mammalian achaete-scute and atonal homologs regulate neuronal versus glial fate determination in the central nervous system. EMBO J 19:5460-5472.

Toresson H, Potter SS, Campbell K (2000) Genetic control of dorsal-ventral identity in the telencephalon: opposing roles for Pax6 and. Gsh2. Development 127:4361-4371.

Wray S, Fueshko SM, Kusano K, Gainer H (1996) GABAergic neurons in the embryonic olfactory pit/vomeronasal organ: maintenance of functional GABAergic synapses in olfactory explants. Dev Biol 180:631-645.

Yun K, Fischman S, Johnson J, Hrabe de Angelis M, Weinmaster G, Rubenstein JLR (2002) Modulation of the notch signaling by Mash1 and Dlx $1 / 2$ regulates sequential specification and differentiation of progenitor cell types in the subcortical telencephalon. Development 129:5029-5040.

Zhong TP, Rosenberg M, Mohideen M-APK, Weinstein B, Fishman MC (2000) gridlock, an HLH gene required for assembly of the aorta in zebrafish. Science 287:1820-1824.

Zhou Q, Anderson DJ (2002) The bHLH transcription factors OLIG2 and OLIG1 couple neuronal and glial subtype specification. Cell 109:61-73.

Zhou Q, Choi G, Anderson DJ (2001) The bHLH transcription factor Olig2 promotes oligodendrocyte differentiation in collaboration with $\mathrm{Nkx} 2.2$. Neuron 31:791-807.

Zimmerman L, Parr B, Lendahl U, Cunningham M, McKay R, Gavin B, Mann J, Vassileva G, McMahon A (1994) Independent regulatory elements in the nestin gene direct transgene expression to neural stem cells or muscle precursors. Neuron 12:11-24. 